\title{
APRENDIZAJE Y ENSEÑANZA DE LA ANTROPOLOGÍA DE LA INFANCIA EN YUCATÁN (MÉXICO). El EFECTO CAUTIVADOR DE UN ÁMBITO DE ESTUDIO
}

\author{
Guadalupe REYES DOMÍNGUEZ*
}

\section{INTRODUCCIÓN}

Mi PRÁCTICA DOCENTE en una universidad pública del sureste mexicano y, en particular, mi rol de directora de tesis me condujeron al campo de la antropología de la niñez. En cierta ocasión una alumna solicitó mi asesoría para realizar un estudio etnográfico con niños aficionados a un juego que, por su asociación con un programa de televisión infantil, se había puesto de moda en la ciudad. La joven había enfrentado la crítica de sus compañeros e incluso de algunos colegas que la censuraban por ocuparse de algo "banal" y "carente de importancia". Sin mucho entusiasmo, pero intuyendo que el reto me pondría en contacto con un rico campo de conocimiento, acepté apoyarla. Así junto con ella y con otros alumnos interesados en realizar investigaciones sobre juego infantil, me introduje en la literatura académica vinculada al juego de los niños, a su socialización y a la construcción social de infancias diversas.

Poco después fui comisionada por mi universidad para supervisar un programa de servicio social realizado por estudiantes de diversas licenciaturas con niños de primarias públicas. Paulatinamente mi interés por el tema de la infancia creció, llevándome a participar en los debates ciudadanos sobre la defensa de los derechos de los niños, niñas y adolescentes en la región donde vivo ${ }^{1}$. Estas experiencias y mi creciente contacto con lo que ha dado en llamarse "estudios críticos sobre la infancia"2 me generaron numerosos cuestionamientos en torno a la diversidad de formas que asume la niñez, a los factores que intervienen en esta variabilidad, a los significados que los niños dan a su propia vida y a las condiciones que constriñen y estimulan su participación en la dinámica social. Dudas, problematizaciones, sentimientos movilizados en el trayecto se tradujeron en múltiples aprendizajes que enriquecieron mi práctica profesional y en un entusiasmo que, probablemente, animó

\footnotetext{
* Guadalupe Reyes Domínguez, Facultad de Ciencias Antropológicas de la Universidad Autónoma de Yucatán, profesora-investigadora, mardomin@ correo.uady.mx,

http://www.antropologia.uady.mx/programas/antropologiasocial/reyes.php

1 En 2007 participé -- junto con académicos de diversas instituciones, funcionarios públicos, docentes de educación básica y activistas de organizaciones civiles - en las Mesas de Diálogo Social por la Infancia, que culminaron con una propuesta presentada a la Cámara de Diputados local, la cual preparaba, por aquel entonces, la Ley de Derechos de los Niños, Niñas y Adolescentes del Estado de Yucatán.

${ }^{2}$ Heterogénea corriente con dos afluentes principales: childhood studies (surgidos hacia la década de los ochentas del siglo pasado entre académicos de habla inglesa y un subcampo de la antropología que hasta hace poco era poco visible: la antropología de la niñez. Al interior de esta heterogénea corriente se distinguen múltiples enfoques (véase (Reyes, 2014), sin embargo, coinciden en que los niños tienen mucho que decir sobre el mundo y son actores sociales importantes en la construcción de la realidad social.
} 
a algunos estudiantes de antropología de mi institución a adentrarse en el estudio de las experiencias infantiles. En este trabajo comparto algunas reflexiones surgidas de este aprender y enseñar antropología de la infancia en la Universidad Autónoma de Yucatán (UADY); a la vez comento una obra colectiva, de reciente publicación, que puede ser útil en la formación de nuevos estudiosos de la niñez.

\section{LA ANTROPOlogía de LA NiÑEZ EN MÉXICO Y YUCATÁN, UN CAMPO DISPERSO Y POCO VISIBLE}

Antes de relatar mi experiencia docente en el ámbito de la antropología de la infancia quiero ubicar el contexto académico en el que ésta ha tenido lugar. Le Vine (2007), Lancy (2010), Pachón (2009) y Montgomery (2009), entre otros, han mostrado que prácticamente desde los inicios de la antropología algunos antropólogos se ocuparon de la infancia y dieron cuenta de que las condiciones y formas de la niñez varían en los distintos contextos culturales. Sin embargo, hasta muy recientemente los niños tuvieron un lugar periférico en la disciplina (Hirschfeld 2002; Colángelo 2005; Szulc 2006; Lopes \& Nunes, 2008; De León 2005).

En México la marginalidad de los estudios etnográficos sobre la infancia ha sido similar a la ocurrida a nivel internacional. Un ejemplo de lo anterior, como mostré en otro trabajo (Reyes 2014: 31), es el hecho de que de 644 tesis de maestría y 253 de doctorado presentadas en el país en alguna de las ciencias antropológicas entre 2002 y 2008, sólo 18 tuvieron a los niños y sus vidas como eje de análisis y en ese periodo ningún congreso centrado en estudios antropológicos sobre la niñez fue celebrado en el país. Lo anterior no quiere decir que en el período considerado no se hayan publicado etnografías que aludieran a la vida de los niños, de hecho, en muchos trabajos y actividades académicas se presentaron descripciones etnográficas vinculadas con las experiencias de los niños mexicanos, pero esto se hizo teniendo como foco otros temas, tales como parentesco, organización doméstica, ritos de paso, educación, trabajo informal, migraciones o identidades sociales.

En contraste, durante la última década los seminarios, congresos y publicaciones antropológicas centrados en la niñez han ido en aumento. A modo de ilustración pueden mencionarse los seminarios-taller sobre antropología de la infancia organizados en 2013, 2015 y 2017 en El Colegio de San Luis; el Simposio Internacional Encuentros Etnográficos con Niñas, Niños, Adolescentes y Jóvenes en Contextos Educativos realizado en Oaxaca en 2013; el Seminario Estudios de las Infancias: Aproximaciones y Retos, que tuvo lugar en la Universidad Autónoma Metropolitana en 2012 y el Seminario Antropología de la Niñez en Contextos de Desigualdad realizado en la Escuela Nacional de Antropología e Historia en 2011. Por otra parte, diversos investigadores mexicanos han consolidado una trayectoria en el estudio antropológico de la niñez; tal es el caso de Lucía Mantilla, Neyra Alvarado, Citlali Quecha, Valentina Glockner, Nancy Villanueva entre otros. Asimismo, revistas mexicanas de antropología que cuentan con gran prestigio han 
centrado alguno de sus números en investigaciones sobre infancia ${ }^{3}$. A la vez, algunos eventos interdisciplinarios que en torno al estudio de la niñez reúnen a diversidad de investigadores sociales, han mostrado continuidad por varios años (véase http://www.uam.mx/cdi/inicio.html).

En Yucatán los estudios antropológicos en los que los niños ocupan un lugar central aún son escasos y dispersos. Etnografías tradicionales hablaron, sin ser su tema de interés fundamental, acerca de los niños en situaciones específicas, por ejemplo describieron su participación - imitando el sonido de las ranas - en la ceremonia agrícola con que los campesinos solicitan lluvia a sus deidades; analizaron el simbolismo del hetsmek, ritual maya de asignación de roles sociales que se realiza a niños y niñas en los primeros meses de edad, o describieron la participación infantil en el trabajo doméstico y en las estrategias familiares de subsistencia.

A fines del pasado siglo e inicios del presente los niños comenzaron a ser sujetos de estudio protagónicos en algunas etnografías, pero, aun así, permanecieron subordinados a otros intereses de exploración, tales como crianza en comunidades mayas, albergues escolares indígenas, procesos de socialización, adquisición de la lengua y representaciones de la ciudad. Todavía es poco lo que sabemos sobre las autopercepciones de los niños de la entidad y sobre los significados que dan al mundo en el que están inmersos (Reyes 2018).

\section{LA FORMACIÓN DE ESTUDIANTES DE LA UADY EN EL ÁMBITO DE ANTROPOLOGÍA DE LA INFANCIA}

Al empezar a incursionar en el estudio de la niñez mis alumnos y yo encontramos que las bibliotecas locales tenían escaso material que abordara la temática. Para instruirnos sobre los debates contemporáneos en este ámbito tuvimos que acudir a otros medios. En viajes y compras a distancia fuimos reuniendo algunas obras antropológicas, clásicas y contemporáneas, centradas en el estudio de las infancias y accedimos a una gama de trabajos disponibles en internet. La consigna fue siempre compartir lo que cada quien encontrara y, según las habilidades de cada uno, apoyar a los demás traduciendo ideas centrales de textos escritos en idiomas distintos al español. Así fuimos nutriendo nuestra comprensión del tema con aportaciones de antropólogos ingleses, estadounidenses, brasileños, argentinos, colombianos, españoles y, por supuesto, mexicanos. Sólo recientemente comenzamos a acercarnos a la literatura antropológica sobre infancia escrita en francés.

Al principio la discusión de los textos que encontrábamos fue guiada por el azar. Poco a poco, algunos tópicos se revelaron como fundamentales y útiles para reflexiones epistemológicas, teóricas, metodológicas y éticas. Finalmente, con la experiencia ganada mediante la revisión de textos y las exploraciones en campo, pude organizar un taller de investigación en el que alumnos interesados en el estudio antropológico de la niñez pudieran formarse y compartir experiencias. Estudiantes

\footnotetext{
${ }^{3}$ Véanse el número 47 de Alteridades, publicado en 2014 y el número 64 de Cuicuilco, presentado en 2015.
} 
de varias generaciones han participado ya en el taller, algunos de forma temporal, otros desde el segundo año de su carrera hasta concluir la licenciatura en Antropología (con duración de cuatro años). Como resultado se ha generado una decena de tesis y otras investigaciones se encuentran en curso. Se han abordado experiencias infantiles en Yucatán y otros estados del país (tanto en ámbitos rurales, como en urbanos) relacionando la participación infantil en la vida social con temas diversos, tales como roles de género, organización de la vida doméstica, juegos, rituales del ciclo de vida, movilidad en espacios públicos, formación escolar, prácticas religiosas, construcción de identidades, percepción de la violencia e imaginarios sobre la vida buena y feliz. A diferencia de trabajos anteriores, el foco estuvo en la experiencia infantil sobre estos ámbitos.

En el taller he buscado propiciar que, antes de formular su protocolo de investigación e iniciar sus trabajos de campo, los estudiantes:

- Problematicen las concepciones hegemónicas sobre la niñez y sus propias nociones de ésta.

- Analicen el desarrollo histórico del concepto infancia en las llamadas sociedades occidentales.

- Lean críticamente y contrasten textos etnográficos, estudios históricos, reportes periodísticos, informes gubernamentales que dan cuenta de variadas formas de vivir y entender la infancia.

- Discutan diversos enfoques teóricos empleados en las ciencias sociales para abordar el estudio de la niñez.

- Evalúen los alcances y limitaciones de distintas alternativas metodológicas desarrolladas por la antropología para el estudio de la infancia, así como las dificultades de acceso a las "voces infantiles".

- Analicen las implicaciones de las técnicas de investigación comúnmente utilizadas en el estudio de la niñez, considerando el tipo de conocimiento que generan, las relaciones que suscitan entre los niños y el investigador, su conexión con formas alternativas de representación y escritura etnográfica.

En este proceso necesariamente tocamos temas clásicos de la reflexión antropológica tales como las relaciones entre naturaleza y cultura, cambio y continuidad cultural, agencia y estructura, infancia y vida adulta, relativismo y generalización. Analizamos la porosidad y dinamismo de las fronteras que "delimitan" las mencionadas oposiciones. Discutimos también las implicaciones del trabajo etnográfico con perspectivas émic y étic. Contrastamos enfoques de investigación distanciados, estudios colaborativos y abordajes implicados en la vida del grupo, distinguiendo relaciones de poder entre investigadores y sujetos participantes En nuestras reflexiones tiene cabida asimismo el tema de las repercusiones éticas y políticas del quehacer antropológico (durante el trabajo de 
campo y con posterioridad a éste) y de las aportaciones posibles de la antropología de la infancia a la política pública y la acción ciudadana.

Tras formular su proyecto de investigación en el taller, los estudiantes realizan una estadía de un semestre en campo. Algunos se ubican en una misma localidad para poder apoyarse mutuamente. Otros efectúan su trabajo de manera individual. Durante este lapso las sesiones grupales se suspenden y mi asesoría a los proyectos se vuelve más personal. Al regresar inician una etapa rica en reflexiones y retos. Comparten sus experiencias de investigación y las emociones que éstas movilizaron; hacen cuestionamientos a su formación en el aula; comentan sus dificultades para plasmar en el papel lo aprendido con los niños; intercambian sus inquietudes respecto a las posibles formas de reciprocidad con quienes les albergaron y compartieron la vida durante el trabajo de campo. Es tiempo de comentar y ensayar posibles ensamblajes de los datos, revisar y rehacer borradores, pulir y precisar ideas, pero, sobre todo, de repensar expectativas laborales, trayectorias académicas y actuaciones personales en la vida social. El diálogo entre compañeros y la relectura de textos de antropológicos a la luz de las experiencias en campo nos enriquece a todos.

Como complemento de esta formación algunos estudiantes se han involucrado en proyectos de extensión universitaria con niños, en asociaciones de la sociedad civil orientadas hacia la infancia o han colaborado como asistentes de investigación en mis trabajos etnográficos sobre la niñez yucateca.

Es mucho lo que falta en el camino de comprender y hacer visible la participación de los niños y las niñas en la dinámica social. Se requiere mantener vivas las reflexiones sobre los significados que ellos otorgan a sus vidas, sobre las habilidades y potencialidades que manifiestan, sobre los procesos que los constriñen y que generan vulnerabilidad para muchos. La tarea no es sencilla; la formación de nuevos investigadores en este subcampo de la antropología demanda sumar esfuerzos y es, en este sentido, que la obra que comento a continuación puede ser un punto de apoyo para quienes ejercen la docencia o quieren incursionar en este ámbito.

\section{MÚlTIPLES MIRADAS HACIA LAS INFANCIAS MEXICANAS CONTEMPORÁNEAS.}

Desde tiempo atrás hasta nuestra época han existido en la literatura antropológica -aunque con poca visibilidad - obras colectivas que compilan trabajos sobre la infancia (por ejemplo Whiting 1967; LeVine \& New 2008; Lopes, Lopes \& Nunes 2008; Díaz \& Vázquez 2010). En contraste, en México los resultados de investigaciones realizadas en torno a la temática se encuentran dispersos. Es por ello que me parece relevante dedicar unas líneas a la obra Infancias mexicanas contemporáneas en perspectiva, libro editado por Neyra Alvarado, Élodie Razy y Salvador Pérez y publicado por el Colegio de San Luis. La obra reúne las reflexiones de 20 investigadores de la niñez, procedentes de 11 instituciones distintas (tanto académicas, como asociaciones civiles) y ofrece un botón de muestra acerca de la 
diversidad de infancias presentes en nuestro país. Las descripciones etnográficas ahí recopiladas abarcan escenarios urbanos y rurales de una docena de entidades federativas, incluyen observaciones sobre los niños de ocho grupos étnicos $y$, en varios casos (como los de los niños jornaleros, los migrantes del campo a la ciudad, los participantes en espectáculos itinerantes o los peregrinos), siguen a los menores de edad y sus familias en sus desplazamientos por el territorio. Casi todos los ensayos se inscriben en la presente década, pero algunos nos llevan a otros momentos de la vida nacional o bien, hacen contrastes diacrónicos.

A través de los diversos capítulos los autores se mueven desde los padres fundadores de la antropología y sus aportaciones al estudio de la infancia, hasta investigaciones y debates contemporáneos. Algunos entretejen sus propuestas epistemológicas, teóricas y metodológicas para el estudio de la niñez, con el interés en políticas públicas vinculadas a asuntos de difícil atención, tales como la obesidad infantil, la prostitución y drogadicción entre menores, la educación multicultural, la equidad de género, la explotación laboral de los niños e, incluso, la venta de menores. El tono general de la obra, sin embargo, rehúsa enfocar a los niños como si la vulnerabilidad fuera una característica natural o la más sobresaliente de quienes no han llegado a la adultez. Por el contrario, los autores se alejan de explicaciones simplistas y buscan dar cuenta de las complejas situaciones sociales y culturales que producen vulnerabilidades específicas en cada contexto, subrayando el reto de crear mejores condiciones para que los niños puedan crecer, sin importar su sexo, etnia o sector social de pertenencia.

Por otra parte, y también alejándose de la noción de vulnerabilidad natural del niño, la mayoría de los trabajos presentados en Infancias mexicanas contemporáneas proponen acercamientos que ven al niño como sujeto actuante y no mero recipiente pasivo de las condiciones externas, de las prácticas adultas o de los constreñimientos de las estructuras biológica, mental o social. Así, a lo largo del texto apreciamos el despliegue de la actividad infantil en distintos ámbitos: niños participantes en tareas domésticas, agrícolas y ganaderas, actores de espectáculos circenses, inventores de juegos, transmisores de conocimientos acerca de seres naturales y sobrenaturales de su entorno, o bien como sujetos que manejan las nuevas tecnologías de la comunicación, que piden apoyos al gobierno, que cuidan de otros miembros de la familia, que generan acciones solidarias durante el recreo escolar, que re-significan prácticas religiosas y negocian normas familiares.

Si bien todos los autores coinciden en que los niños no son entes pasivos ni esclavos de las estructuras, el libro problematiza en varios momentos la noción de agencia infantil. Élody Razy muestra en su capítulo la ambigüedad del concepto e invita expresamente a los lectores a evitar su aplicación acrítica; propone cuestionarlo y definirlo primero, explorar la naturaleza y efectos de esta noción, sus relaciones con otros conceptos tales como el de responsabilidad y el de conocimiento informado. Norma Ramos, a su vez, sugiere estar atentos a la intervención adulta que el investigador puede encontrar muchas veces oculta tras la supuesta agencia 
infantil o tras la llamada "voz de los niños". Así, Infancias mexicanas contemporáneas ofrece material valioso para analizar uno de los conceptos más relevantes en las discusiones actuales sobre la niñez.

Además, el libro presenta variadas formas de relación entre los niños y los adultos de su entorno y múltiples mecanismos para inducir la incorporación infantil a la vida grupal: firmeza y dulzura, rudeza, acompañamiento, provocación, contacto físico y distancia, vigilancia y abandono, evitación y supervisión, todo ello aparece entretejido en el texto, dando cuenta de la movilización de emociones diversas que tienen lugar en procesos que se resisten a ser etiquetados con conceptos hasta hoy disponibles. ¿Socialización, enculturación, introducción a la vida comunitaria, emergencia de la persona social? ¿Cómo nombrarlos?

Los textos incluidos en Infancias mexicanas contemporáneas ofrecen asimismo un panorama amplio respecto a las relaciones de los niños con el espacio y a los significados infantiles de éste. Como resultado, quien utilice en la docencia la obra aquí comentada podrá contar con material para adentrarse en el cuestionamiento de dicotomías ligadas a lo espacial, que con frecuencia se asumen como si fueran no problemáticas: sagrado / profano; público / privado; serio / lúdico; indígena / no indígena; físico / virtual o bien local / global.

La reflexión sobre aspectos metodológicos de la investigación con niños es de importancia central al formar nuevos antropólogos orientados al estudio de la niñez; a este respecto el libro brinda diversos recursos. Neyra Alvarado, en su trabajo, aboga por una antropología de la infancia que en vez de aplicar teorías y conceptos a priori, los construya con la aportación del conocimiento local. Propone una antropología intuitiva de larga duración, que se deja sorprender por la realidad, apoyada en relaciones de confianza con los sujetos de estudio y alejada de diseños rígidos,

En varios de los capítulos se insiste en la necesidad de aproximarse a las experiencias de los niños como seres relacionales que: a) interactúan con las otras categorías de su grupo, en el marco de concepciones específicas sobre competencias, responsabilidades, prohibiciones y estatus correspondientes a diversas edades biológicas y sociales; y b) cuyas vidas no son independientes de procesos que entretejen la particularidad de sus vivencias con procesos locales, regionales, nacionales y globales.

Desde la introducción al libro se señala que el estudio antropológico de los niños no requiere una metodología especial o de técnicas novedosas, sino del seguimiento minucioso de procesos en los que ellos intervienen cotidianamente. La mayoría de los trabajos parten de la observación prolongada y contextualizada y en general, recurren al análisis de las prácticas infantiles como expresión de intereses, intenciones, deseos, dispositivos de poder. No obstante, el lector encontrará en la obra ejemplos de variadas estrategias de investigación. Hallará tanto investigaciones 
centradas en una situación particular como estudios comparativos (distintos casos, momentos históricos o condiciones familiares). Diversas técnicas son también ejemplificadas: desde acompañamiento a los niños en sus actividades diarias o en eventos especiales, hasta recorridos comentados por los menores, elaboración de dibujos y video-cartas, juegos conjuntos, deconstrucción de discursos y análisis estadístico de palabras asociadas espontáneamente por los chicos.

El docente interesado en formar nuevas generaciones de investigadores de la infancia podrá mostrar también múltiples estilos de escritura etnográfica a través de los trabajos contenidos en Infancias Mexicanas en Perspectiva. Algunos autores recurren a sobrias y detalladas descripciones étic que relacionan las experiencias infantiles con distintas esferas culturales, otros buscando dar cuenta de sentidos y emociones, emplean la inserción de diálogos o la transcripción de conversaciones tanto en español como en el idioma original en el que fueron expresadas. La reflexión teórica se entreteje en algunos capítulos con historias individuales y en otras páginas aparece hilvanada a datos estadísticos o a estudios comparativos. En todo momento se vuelve evidente la necesidad que tenemos de problematizar una idea que se ha vuelto retórica: la de que el investigador recoge y transmite las "voces de los niños", como si éstas fueran diáfanas, incontaminadas por relaciones de poder o ajenas a emociones que se expresan en formas particulares en los diversos contextos.

Más aún, Infancias Mexicanas en Perspectiva previene contra el uso irreflexivo de "la voz del niño". Nos recuerda que la idea de dar voz al niño tiene tintes etnocéntricos e invita a reflexionar, en cada investigación concreta ¿a quién sirve la visibilización de las voces infantiles? ¿Qué pasa cuando el etnógrafo abandona el campo, una vez que el niño ha alcanzado cierto nivel de conciencia en el proceso de "darle voz"? Se plantea en la obra la necesidad de desarrollar una ética procesual, construida durante el trabajo de campo en vez de atarse a protocolos éticos cerrados. Una ética inseparable de la reflexividad individual que suponen las situaciones siempre imprevistas del trabajo de campo.

Por lo antes expuesto, considero que Infancias Mexicanas en Perspectiva puede constituirse en un buen punto de apoyo para abordar desde múltiples ángulos la situación de los niños en México y también para enseñar y aprender antropología de la infancia. Desde ahí, como el propio texto lo propone al incluir un caso boliviano, transitar a la discusión de otras infancias y al diálogo con diversas tradiciones en el estudio de las experiencias infantiles.

\section{BIBLIOGRAFÍA}

Alvarado N., Razy E. \& Perez S. (eds.) 2018 Infancias Mexicanas contemporáneas. Perspectivas pluridisciplinarias. San Luis Potosí : El Colegio de San Luis.

COLANGELO M.A. 2005 « La mirada antropológica sobre la infancia. Reflexiones y perspectivas de abordaje", Seminario Internacional La Formación Docente entre el siglo XIX y el siglo XXI, Ministerio de Educación de Argentina :

http://www.me.gov.ar/curriform/publica/oei_20031128/ponencia_colangelo.pdf 
DE LEON L. 2005 La llegada del alma. Lenguaje, infancia y socialización entre los mayas de Zinacantán. México : CIESAS / CONACULTA/INAH.

DiAZ M. \& VAZQUEZ S. (eds.) 2010 Contribuciones a la antropología de la infancia. Los niños como campo de agencia, autonomía y construcción cultural. Bogotá : Pontificia Universidad Javeriana.

ESCUELA NACIONAL DE ANTROPOLOGIA E HISTORIA 2015 Número especial : «Infancia y Crianza ». HIRSCHFELD L. 2002 «Why don't anthropologists like children? ", American Anthropologist 104(2) : 611-627.

LANCY D. 2010 The Anthropology of Childhood. Cherubs, Chattel, Changelings. Nueva York: Cambridge University Press.

LEVINE R. 2007 «Ethnographic Studies of Childhood: A Historical Overview», American Anthropologist 109(2) : 247-259.

LeVine R. \& New R.S. 2008 Anthropology and Child Development. A Cross-Cultural Reader. Hoboken : Wiley-Blackwell.

LOPES A., LOPES A.V. \& NunES A. 2008 Crianças indígenas. Ensaios Antropológicos. Sao Paulo: Global Editora.

MONTGOMery H. 2009 An Introduction to Childhood. Anthropological Perspectives on Children's Lives. Oxford : Wiley-Blackwell.

PACHON X. 2009 «¿Dónde están los niños? Rastreando la mirada antropológica sobre la infancia », Maguare (23) : 433-469.

REYES G. 2018 «Azar, empatía y reciprocidad. Andanzas en el acercamiento a las voces infantiles » (78-103), in Angelotti G., Cecilia L., Guadalupe R., Violeta G. \& Luis V. (eds.) Experiencias etnográficas en Yucatán. Mérida : Universidad Autónoma de Yucatán.

REYES G. 2014 «Imágenes acerca del niño en dos colectivos infantiles con ascendiente maya », Alteridades 24(47) : 31-42.

SZULC A. 2006 «Antropología y niñez : de la omisión a las culturas infantiles » (25-50), in Wilde G. \& Schamber P. (eds.) Culturas, comunidades y procesos urbanos contemporáneos. Buenos Aires: Editorial SB.

UNIVERSIDAD AUTONOMA METROPOLITANA 2014 Número especial : «El estudio de las infancias » Alteridades 24(47).

WHITING B. 1963 Six Cultures : Studies of Child Rearing. New York : Ed. Wiley. 